\title{
Retraction Note to: A New Information Exposure Situation Awareness Model Based on Cubic Exponential Smoothing and Its Prediction Method
}

Weijin Jiang, Yirong Jiang, Jiahui Chen, Yang Wang, and Yuhui Xu

\author{
Retraction Note to: \\ Chapter "A New Information Exposure Situation Awareness \\ Model Based on Cubic Exponential Smoothing \\ and Its Prediction Method" in: Y. Sun et al. (Eds.): \\ Computer Supported Cooperative Work and Social Computing, \\ CCIS 1042, https://doi.org/10.1007/978-981-15-1377-0_17
}

The authors have retracted this article [1] because of overlap with doctoral dissertation [2]. Figures 5, 6 and 7 were taken from the dissertation without permission or attribution. Part 2.3 of the article "Evaluation of information Outburst prediction model" quotes the data from this doctoral dissertation and makes some erroneous changes. All authors agree to this retraction.

[1] Jiang, W., Jiang, Y., Chen, J., Wang, Y., Xu, Y.: A new information exposure situation awareness model based on cubic exponential smoothing and its prediction method. In: Sun, Y., Lu, T., Yu, Z., Fan, H., Gao L. (eds.) Computer Supported Cooperative Work and Social Computing. ChineseCSCW 2019. Communications in Computer and Information Science, vol. 1042. Springer, Singapore (2019). https://doi. org/10.1007/978-981-15-1377-0_17

[2] Yi, C.: Research on Mechanisms of Information Propagation And Control Strategies in Social Networks. Dissertation at Harbin University of Science and Technology (2016) 